\title{
Attraction of Melitaea cinxia butterflies to previously-attacked hosts : a likely complement to known Allee effects?
}

\section{Singer, Michael C.}

2017-05

Singer , M C , Kuussaari , M \& van Nouhuys, S 2017 , ' Attraction of Melitaea cinxia butterflies to previously-attacked hosts : a likely complement to known Allee effects? ' , Annales Zoologici Fennici, vol. 54 , no. 1-4 , pp. 205-211 . https://doi.org/10.5735/086.054.0118

http://hdl.handle.net/10138/208042

https://doi.org/10.5735/086.054.0118

publishedVersion

Downloaded from Helda, University of Helsinki institutional repository.

This is an electronic reprint of the original article.

This reprint may differ from the original in pagination and typographic detail.

Please cite the original version. 


\title{
Attraction of Melitaea cinxia butterflies to previously- attacked hosts: a likely complement to known Allee effects?
}

\author{
Michael C. Singer ${ }^{1}$, Mikko Kuussaari ${ }^{2}$ \& Saskya van Nouhuys ${ }^{3}$ \\ 1) Biological Sciences, Plymouth University, Drake Circus, Plymouth PL4 8AA, U.K. \\ 2) Finnish Environment Institute, Natural Environment Centre, P.O. Box 140, Fl-00251 Helsinki, \\ Finland \\ 3) Metapopulation Research Centre, Department of Biosciences, P.O. Box 65, Fl-00014 University \\ of Helsinki, Finland
}

Received 25 Jan. 2017, final version received 30 Mar. 2017, accepted 21 Mar. 2017

Singer, M. C., Kuussaari, M. \& van Nouhuys, S. 2017: Attraction of Melitaea cinxia butterflies to previously-attacked hosts: a likely complement to known Allee effects? - Ann. Zool. Fennici 54: 205-211.

Clumped distributions of herbivorous insect eggs often result from independent assessments of individual plants by different ovipositing females. Here we ask whether, in addition, plants might be rendered more or less attractive to ovipositing Melitaea cinxia butterflies by presence of conspecific eggs and/or by prior larval attack. Both eggs and larval damage rendered Veronica spicata plants significantly more acceptable; the effect of eggs was particularly strong. Larval damage caused a marginally significant increase in acceptability of Plantago lanceolata, but there was no trend for an effect of eggs on this host. Variable oviposition preferences of Melitaeine butterflies are known to drive their metapopulation dynamics by affecting rates of emigration and patch colonization. Therefore variable host acceptability, as documented here, should do likewise, reducing emigration rates at high population densities where $V$. spicata is present in the landscape and complementing Allee effects that are already known in this system.

\section{Introduction}

With typical panache, Ilkka Hanski began a talk in 1994 like this: "We have sequenced an entire landscape comprising 1.6 kilopatches." Each year for five years he and his entourage had counted the conspicuous communal larval webs of the Glanville fritillary butterfly, Melitaea cinxia, on each of two host plants, Veronica spicata and Plantago lanceolata, in 1600 habitat patches across the Åland Islands. Early analyses of these data examined influences of patch size, spacing and dispersal on metapopulation dynamics (Hanski et al. 1994, 1995, Kuussaari et al. 1996). As the dataset grew over the years, including ever more kilopatches (Ojanen et al. 2013), it became possible to analyse how patch colonization and metapopulation dynamics were influenced by host composition of the patches and host preferences of the butterflies (Kuussaari et al. 2000, Hanski \& Singer 2001, Hanski \& Heino 2003). Individuals from patch networks in which the 
insects fed principally on Veronica were not at all different from those sampled from Plantagofeeding networks in terms of larval performance (van Nouhuys et al. 2003). In contrast, they were clearly and genetically different in oviposition preference (Kuussaari et al. 2000). The adaptive significance of this differentiation is not known, but if it exists it is probably connected with hostfinding efficiency (Singer 2015).

Genetic variation of post-alighting oviposition preference for host species, coupled with variable host composition of habitat patches, drove biases in both emigration and patch colonization. Two metapopulation-level effects of these biases emerged. First, in local patch networks where Veronica was more preferred, empty patches containing principally Veronica were more likely to be colonized than Plantagodominated patches (Hanski \& Singer 2001). Second, again in local patch networks where Veronica was more preferred, host use in occupied patches was more biased towards Veronica than expected from its relative abundance in each patch (Kuussaari et al. 2000).

These metapopulation-level effects were driven by matches and mismatches between the genetically-determined oviposition preferences of the insects and the host compositions of the patches in which they found themselves. In consequence, any factor that systematically affected host acceptability to the butterflies would be expected to add to these metapopulation effects. Here, we ask whether prior attack by $M$. cinxia affects host acceptability to females arriving subsequently and assessing those hosts for oviposition. Increases in host acceptability in response to attack would be expected to complement the Allee effects already documented in this system (Kuussaari et al. 1998) by reducing emigration rates from patches with dense local $M$. cinxia populations. The metapopulation level effect of this would be to increase the stability of established patches, and decrease the successful colonization of new patches by one or just a few founder individuals.

\section{Methods}

Our aim was to study whether experimentally- manipulated attacks on host plants by adult and larval $M$. cinxia affected the acceptabilities of those hosts to searching butterflies arriving after those attacks. To do this, we obtained stocks of $M$. cinxia, $P$. lanceolata and $V$. spicata from the Åland Islands (Finland), within the intensivelystudied $M$. cinxia metapopulation. To study the effect of butterfly eggs on P. lanceolata, the plants were grown in a greenhouse in Åland in potting soil mixed with sand from Åland. The plants for the rest of the experiments were grown in a greenhouse in Austin, Texas, in sterilized granitic sand from Sequoia National Forest, California, resembling soil in the plants' natural habitat.

For the experiment using eggs laid on $V$. spicata we selected matched pairs of plants that were either clones or siblings from the same habitat patch. Criteria used in matching included size, morphology and phenology. We then randomly selected one member of each pair to receive eggs from a motivated $M$. cinxia female that had not been allowed to lay eggs for one day prior to the experiment and that could therefore be readily induced to oviposit on a plant chosen by the experimenter. Eggs were laid on the chosen plants without disturbing the plants in any way, other than by placing the butterflies upon them. The experiment was repeated with plants that were not clones, with members of each pair chosen from different habitat patches.

For the experiment using eggs laid on $P$. lanceolata plants were paired by size and phenology. One member of each pair was chosen randomly to have eggs laid on it. This plant was put in a sleeve cage with a mated fed M. cinxia female that had oviposition experience but had not laid eggs in the last 24 hours. The other plant was placed in a sleeve cage with no butterfly, and they were both left for the day in the greenhouse.

For the experiments on responses to prior larval damage we again used matched plant pairs and randomly chose one member of each pair to receive post-diapause larvae, which were removed after they had eaten around $50 \%$ of the foliage. To assess effects of experimental treatments on host acceptability to the butterflies we waited from 2 to 5 days after eggs had been laid or one month after larvae had been removed. We then tested each experimental plant pair with a different female butterfly. 
For all experiments except the one using eggs laid on $P$. lanceolata butterflies were fed and allowed to bask in natural sunlight before each set of trials. We then staged repeated encounters between each insect and the two members of a plant pair in alternation, following a protocol described in Singer et al. (1992). Insects were not allowed to oviposit, but attempts to do so were scored as acceptances of the test plant. If the attacked plant was accepted by the insect and the unattacked plant subsequently rejected, we recorded a preference for the attacked plant. Insects that did not discriminate between the test plants were allowed to lay eggs and re-tested. If, after several re-tests, they made no discrimination, the result for that plant pair was recorded as no difference in acceptability.

The experiment on response to eggs laid on P. lanceolata was done differently. Four $1 \times 1 \times$ $0.8 \mathrm{~m}$ mesh cages were placed in the greenhouse, spread several meters apart. A pair of plants (with and without eggs) was set in each cage $50 \mathrm{~cm}$ apart. Fed mated female butterflies were introduced to each cage in the morning, and left for the day with access to honey water. At the end of the day we searched for and counted egg clusters on the plants. When only one plant received a cluster, that plant was recorded as more acceptable; when both plants received eggs, we recorded them as equal acceptability. This procedure was repeated with 32 different butterflies and plant pairs on eight sunny days. The number of eggs in each cluster was counted.

Analyses of oviposition choice were by a two-tailed binomial test, using the null hypothesis of equal acceptability of control or experimental plants and excluding from analysis those plant pairs within which the insects failed to discriminate. We analysed the egg clutch size for the experiment on response to eggs laid on $P$. lanceolata using a $t$-test. In the cases that both plants received eggs in that experiment we compared the egg cluster size using a paired $t$-test.

\section{Results}

Effects of larval feeding on plant acceptability were significant and equivalent on the two hosts (Table 1), with greater acceptability to ovipositing adults of plants that had experienced prior herbivory. In contrast, effects of eggs were apparently diverse. Eggs laid on $V$. spicata caused a clear increase of plant acceptability, while those laid on $P$. lanceolata had no detectable influence (Table 1). The result from $P$. lanceolata (which were not cloned) was significantly different from the result from $V$. spicata clones (binomial test: $p=0.02$ ) but not from the result using non-cloned $V$. spicata (binomial test: $p=0.2$ ). In the experiment using $P$. lanceolata, in which oviposition occurred, there was no significant difference in egg clutch sizes between those laid on plants that already contained eggs, and those laid on empty plants, even in trials in which both plant types received eggs (paired $t$-test: $t_{4}=0.1708, p=0.30$ ).

\section{Discussion}

Group living in animals often arises incidentally, with no mean benefit, when individuals attempt to use each other as cover against predators

Table 1. Number of plant pairs (Veronica spicata and Plantago lanceolata) in which the test butterflies preferred the attacked or unattacked individual.

\begin{tabular}{lcccc}
\hline Experiment & $\begin{array}{c}\text { Attacked } \\
\text { plant more } \\
\text { acceptable }\end{array}$ & $\begin{array}{c}\text { Unattacked } \\
\text { plant more } \\
\text { acceptable }\end{array}$ & No difference & $\begin{array}{c}p \\
\text { (binomial test) }\end{array}$ \\
\hline V. spicata cloned, with/without eggs & 18 & 2 & 2 & 0.0002 \\
V. spicata non-cloned with/without eggs & 9 & 2 & 2 & 0.04 \\
P. lanceolata with/without eggs & 8 & 5 & $12,5^{*}$ & 1.0 \\
V. spicata with/without larval damage & 16 & 6 & 8 & 0.02 \\
P. lanceolata with/without larval damage & 15 & 7 & 0.05 \\
\hline
\end{tabular}

\footnotetext{
* No oviposition occurred in 12 trials and both plants were used in five trials.
} 
(Hamilton 1971). It can also confer benefits by enhancing adaptive functions such as camouflage, aposematic display, vigilance and feeding efficiency. Conversely, negative effects of grouping stem from increased competition for food and apparency to enemies. It is not surprising, then, that ovipositing herbivorous insects show a diversity of responses to conspecifics that affect group size, ranging from aversion through neutrality to conspecific attraction. Conspecifics can enhance oviposition, either directly by their presence or indirectly, by their modification of plant quality (Judd \& Borden 1992, Navasero \& Ramaswamy 1993, Prokopy \& Reynolds 1998, Raitanen et al. 2014, Desurmont et al. 2014, Durisko et al. 2014). However, by far the most frequently reported effect is that insects tend to avoid host plants that bear conspecific eggs or larvae (Rothschild \& Schoonhoven 1977, Williams \& Gilbert 1981, Shapiro 1981, Roitberg \& Prokopy 1987, Pettersson 1992, Kumari et al. 2016). The tendency of the butterfly Pieris brassicae to avoid conspecifics was documented more than 100 years ago (Kerbey \& Spence 1858, as cited in Prokopy \& Reynolds 1998). Pieris brassicae are now known to avoid eggs of related species also (Schoonhoven et al. 1990). Shapiro (1981) showed that Pierid butterfly species that laid red eggs avoided them, while those that laid cryptic eggs did not. The avoidance of bright yellow congeneric eggs by Heliconius butterflies has apparently led to the multiple evolutionary origins of specific Heliconius egg mimics produced by their hosts and effective as defences against butterfly oviposition (Gilbert 1982). Many ovipositing insects apply to their hosts a pheromone that deters subsequent oviposition, interacting with other aspects of host quality but generally reducing the acceptability of pheromone-marked hosts. This behaviour has been well studied in true fruit flies, reviewed by Nufio and Papaj (2000).

Insects often have good reason to avoid conspecific eggs. Competition and cannibalism are rife (Wise et al. 2006). Large groups may be apparent to predators or parasitoids (Stamp 1981) and parasitoids may locate their insect hosts using volatiles produced by plants in response to herbivore eggs (Fatouros et al. 2014). Conversely, there may be benefits to some insects of ovipositing preferentially on plants that already have eggs. Prokopy and Reynolds (1998) and Papaj et al. (1992) suggested that adult female Mediterranean fruit flies cue in to the presence of other conspecific adults as an indicator of host plant quality, using "public information" (Danchin et al. 2004) in a manner analogous to the phenomenon of "mate copying" in which females increase their preference for individual males after observing them being accepted by other females. Herbivorous insects may benefit from large group size by enhancement of antipredator defence (Lawrence 1990, Hunter 2000, Riipi et al. 2001), by being better able to overcome host defences (Clark \& Faeth 1997, Campbell \& Stastny 2014, Desurmont et al. 2014) or by constructing better protection against harsh climate (Kuussaari et al. 2004, Kuussaari \& Singer 2017).

The consequences of conflicting effects of local density or group size are sometimes manifest in ambivalent insect behaviour. In walnut flies the physical act of oviposition is facilitated when flies use holes in fruit bored by individuals that have oviposited previously (Nufio \& Papaj 2000). These flies are simultaneously repelled from prior oviposition sites by oviposition deterrent pheromone and attracted to oviposition holes already drilled in the fruit (Nufio \& Papaj 2000).

Clumped egg distributions in the field may occur even when conspecific eggs are avoided, if this avoidance is insufficiently strong to overcome effects on egg distribution of habitat heterogeneity, host dispersion and variance in host plant quality. For instance, oviposition by $M$. cinxia increases with $P$. lanceolata plant size, and differs between genotypes (Reudler Talsma et al. 2008). Therefore, the documented naturally occurring clumping of egg clusters in the field by Melitaeine butterflies including $M$. cinxia (Rausher et al. 1981, Kuussaari et al. 2004) does not necessarily indicate attraction to conspecifics.

Here, we give evidence that past attack by larvae on both hosts rendered them more attractive to ovipositing butterflies. The effect of the presence of eggs was significant on $V$. spicata but not on $P$. lanceolata. However, because of the difference in experimental design between the experiments with P. lanceolata and V. spicata that gave significantly different results, we cannot 
conclude with significance that effects on the two hosts were different, although this is likely. Correspondingly, and potentially through the same mechanism of induced plant response, $V$. spicata becomes attractive to the specialist parasitoid wasp Hyposoter horticola after M. cinxia eggs are laid on it, but P. lanceolata does not (Castelo et al. 2010).

We do not know whether the effect of eggs is direct or indirect. Butterflies may detect eggs directly, as do Heliconius (Gilbert 1982) and Pieris (Shapiro 1981). Alternatively eggs laid on $V$. spicata might have caused induced plant responses (Hilker \& Fatouros 2016), which then rendered the plants more acceptable to ovipositing butterflies. In fact both oviposition and herbivory by $M$. cinxia induce changes in the volatile profile of V. spicata (Pinto-Zevallos et al. 2013).

Like walnut flies, our study insects clearly experience both positive and negative effects of the enhanced larval group size that results when egg clusters share the same small herbaceous host individual. Prediapause $M$. cinxia larval groups have been observed to starve after defoliating their hosts (first author's pers. obs.), and the rate of parasitism of caterpillars by the specialist parasitoid Cotesia melitaearum increases with group size (Lei \& Camara 1999). Conversely, larvae benefit from the strength of the winter nests that only large groups can spin (Kuussaari 1998) and larval survival increases with increasing group size, despite the opposing influence of parasitism (Kuussaari \& Singer 2017).

Local M. cinxia populations in Finland are short-lived and founded by very few individuals, often apparently by single mated females. This conclusion is drawn from the observation that newly colonized populations often contain only a single winter nest of diapausing larvae (Austin et al. 2011). Our experimental results lead to the expectation that these single nests should sometimes comprise amalgamated groups from more than one oviposition event by different females. This mixing can be caused both by multiple oviposition events on the same plant and/or by merging of family groups as the caterpillars move between adjacent plants during feeding. Both of these processes have been documented in Finnish M. cinxia (Kuussaari et al. 2004; Kuussaari \& Singer 2017).
How might the behaviours we discuss here affect (meta)population dynamics? We would expect both hosts, particularly $V$. spicata, to be more acceptable to adults in habitat patches with high insect density. In Melitaeine butterflies the match/mismatch between adult oviposition preferences and the acceptabilities of hosts that those adults encounter influences both emigration rates (Thomas \& Singer 1987) and rates of colonization of empty habitat patches (Hanski \& Singer 2001). Therefore, we expect that the increased acceptability of attacked plants should reduce emigration rates at high population densities and increase them at low densities. These responses would create an Allee effect, augmenting the known Allee effects that result from poor mate location at low densities and from direct responses of adult $M$. cinxia to encounters with conspecifics (Kuussaari et al. 1998). Both male and female butterflies tended to remain longer in patches where they encountered more conspecifics.

The effects shown here thus join a constellation of other factors which complement each other, causing Allee effects, positive densitydependence and clumped population distributions of adults at both within-patch and betweenpatch scales. In order to assess the importance of these various factors for clumped population distributions, we would need to know the strength, not just the direction, of these responses. This would enhance our understanding of the forces affecting population dynamics in this system from which very detailed long-term dynamic data are now available for testing mechanistic hypotheses.

\section{Acknowledgements}

We acknowledge L. Ramakrishnan and J. Jarvi for help with the experiments and Melitaea cinxia butterflies for their apparently enthusiastic co-operation. Partial funding came from the Academy of Finland (grant nos. 218102 and 250444 to $\mathrm{SvN}$ ).

\section{References}

Austin, A., Ovaskainen, O. \& Hanski, I. 2011: Size and genetic composition of the colonizing propagules in a butterfly metapopulation. - Oikos 120: 1357-1365. 
Campbell, S. A. \& Stastny, M. 2014: Benefits of gregarious feeding by aposematic caterpillars depend on group age structure. - Oecologia 177: 715-721.

Castelo, M. K., van Nouhuys, S. \& Corley, J. C. 2010: Olfactory attraction of the larval parasitoid, Hyposoter horticola, to plants infested with eggs of the host butterfly, Melitaea cinxia. - Journal of Insect Science 10: 53, doi:10.1673/031.010.5301.

Clark, B. R. \& Faeth, S. H. 1997: The consequences of larval aggregation in the butterfly Chlosyne lacinia. - Ecological Entomology 22: 408-415.

Danchin, E., Giraldeau, L. A., Valone, T. J. \& Wagner, R. H. 2004: Public information: from nosy neighbors to cultural evolution. - Science 305: 487-491.

Desurmont, G. A., Weston, P. A. \& Agrawal, A. A. 2014: Reduction of oviposition time and enhanced larval feeding: two potential benefits of aggregative oviposition for the viburnum leaf beetle. - Ecological Entomology 39: $125-132$

Durisko, Z., Anderson, B. \& Dukas, R. 2014: Adult fruit fly attraction to larvae biases experience and mediates social learning. - Journal of Experimental Biology 217: 1193-1197.

Fatouros, N. E., Pineda, A., Huigens, M. E., Broekgaarden, C., Shimwela. M. M., Candia, I. A. F., Verbaarschot, P., Bukovinszky, T. 2014: Synergistic effects of direct and indirect defences on herbivore egg survival in a wild crucifer. - Proceedings of the Royal Society B 281: 20141254, doi:10.1098/rspb.2014.1254.

Gilbert, L. E. 1982: The coevolution of a butterfly and a vine. - Scientific American 247: 110-121.

Hamilton, W. D. 1971: Geometry for the selfish herd. Journal of theoretical biology 31: 295-311.

Hanski, I. \& Heino, M. 2003: Metapopulation-level adaptation of insect host plant preference and extinctioncolonization dynamics in heterogeneous landscapes. Theoretical Population Biology 64: 281-290.

Hanski, I., Kuussaari, M. \& Nieminen, M. 1994: Metapopulation structure and migration in the butterfly Melitaea cinxia. - Ecology 75: 747-762.

Hanski, I., Pakkala, T., Kuussaari, M. \& Lei, G. 1995: Metapopulation persistence of an endangered butterfly in a fragmented landscape. - Oikos 72: 21-28.

Hanski, I. \& Singer, M. C. 2001: Extinction-colonization dynamics and host plant choice in butterfly metapopulations. - American Naturalist 158: 341-353.

Hilker, M. \& Fartouros, T. 2016: Resisting the onset of herbivore attack: plants perceive and respond to insect eggs. - Current opinion in plant biology 32: 9-16

Hunter, A. F. 2000: Gregariousness and repellent defences in the survival of phytophagous insects. - Oikos 91: 213-224.

Judd, G. J. R. \& Borden, J. H. 1992: Aggregated oviposition in Delia antiqua: a case for mediation by semiochemicals. - Journal of Chemical Ecology 18: 621-635.

Kuussaari, M. 1998: Biology of the Glanville fritillary butterfly (Melitaea cinxia). - Ph.D. thesis, University of Helsinki.

Kumari, A. \& Kaushik, N. 2016: Oviposition deterrents in herbivorous insects and their potential use in integrated pest management. - Indian journal of experimental biology 54: 163-174.

Kuussaari, M., Nieminen, M. \& Hanski, I. 1996: An experimental study of migration in the Glanville fritillary butterfly Melitaea cinxia. - Journal of Animal Ecology. 65: 791-801.

Kuussaari, M., Saccheri, I., Camara, M. \& Hanski, I. 1998: Allee effect and population dynamics in the Glanville fritillary butterfly. - Oikos 82: 384-392.

Kuussaari, M. \& Singer, M. C. 2017: Group size, and egg and larval survival in the social butterfly Melitaea cinxia. - Annales Zoologici Fennici 54: 213-223.

Kuussaari, M., Singer, M. C. \& Hanski, I. 2000: Local specialization and landscape-level influence of host use in a herbivorous insect. - Ecology 81: 2177-2187.

Kuussaari, M., van Nouhuys, S., Hellmann, J. \& Singer, M. C. 2004: Larval biology of checkerspots. - In: Ehrlich, P. \& Hanski, I. (eds.), On the wings of butterflies: the population biology of checkerspots: 138-160. Academic Press, New York.

Lawrence, W. S. 1990: The effects of group-size and host species on development and survivorship of a gregarious caterpillar Halisidota-caryae (Lepidoptera, Arctiidae). - Ecological Entomology 15: 53-62.

Lei, G. C. \& Camara, M. D. 1999: Behaviour of a specialist parasitoid, Cotesia melitaearum: from individual behaviour to metapopulation processes. - Ecological Entomology 24: 59-72.

Navasero, R. C. \& Ramaswamy, S. B. 1993: Influence of plant age, water stress, larval damage, and presence of conspecific eggs on oviposition by Heliothis virescens on cotton. - Journal of Applied Entomology 115: 97-106.

Nufio, C. R. \& Papaj, D. R. 2001: Host marking behavior in phytophagous insects and parasitoids. - Entomologia experimentalis et applicata 99: 273-293.

Ojanen, S. P., Nieminen, M., Meyke, E., Poyry, J. \& Hanski, I. 2013: Long-term metapopulation study of the Glanville fritillary butterfly (Melitaea cinxia): survey methods, data management, and long-term population trends. - Ecology and Evolution 3: 3713-3737.

Papaj, D. R., Averill, A. L., Prokopy, R. \& Wong, T. Y. 1992: Host-marking pheromone and use of previouslyestablished oviposition sites by the Mediterranean fruit fly (Diptera: Tephritidae). - Journal of Insect Behavior 5: 583-598.

Pinto-Zevallos, D. M., Hellén, H., Hakola, H., van Nouhuys, S. \& Holopainen, J. K. 2013: Induced defenses of Veronica spicata: Variability in herbivore-induced volatile organic compounds. - Phytochemistry Letters 6 : 653-656.

Pettersson, M. 1992: Density-dependent egg dispersion in flowers of Silene vulgaris by the seed predator Hadena confusa (Noctuidiae). - Ecological Entomology 17: 244-248.

Prokopy, R. \& Reynolds, A. 1998: Ovipositional enhancement through socially facilitated behavior in Rhagoletis pomonella flies. - Entomologia Experimentalis et Applicata 86: 281-286.

Raitanen, J., Forsman J. T., Kivela S. M., Maenpaa M. I. \& 
Valkimaki, P. 2014: Attraction to conspecific eggs may guide oviposition site selection in a solitary insect. Behavioral Ecology 25: 110-116.

Rausher, M. D., Mackay, M. D. \& Singer, M. C. 1981: Preand post-alighting host discrimination by Euphydryas editha butterflies: the behavioural mechanisms causing clumped distributions of egg clusters. - Animal Behaviour 29: 1220-1228.

Reudler Talsma, J. H., Biere, A., Harvey, J. A. \& van Nouhuys, S. 2008: Oviposition cues for a specialist butterfly-plant chemistry and size. - Journal of Chemical Ecology 34: 1202-1212.

Riipi, M., Alatalo, R. V., Lindstrom, L. \& Mappes, J. 2001: Multiple benefits of gregariousness cover detectability costs in aposematic aggregations. - Nature 413: $512-514$.

Roitberg, B. D. \& Prokopy, R. J. 1987: Insects that mark host plants. - BioScience 17: 400-406.

Rothschild, M. \& Schoonhoven, L. M. 1977: Assessment of eggload by Pieris brassicae. - Nature 266: 352-355.

Schoonhoven, L. M., Beerling, E. A. M., Klijnstra, J. W. \& van Vugt, Y. 1990: Two related butterfly species avoid oviposition near each others' eggs. - Experientia 46: 526-528.

Shapiro, A. M. 1981: The Pierid red-egg syndrome. - American Naturalist 117: 276-294.
Singer, M. C. 2015: Adaptive and maladaptive consequences of "matching habitat choice:" lessons from a rapidlyevolving butterfly metapopulation. - Evolutionary Ecology 29: 905-925.

Singer, M. C., Vasco, D., Parmesan, C., Thomas, C. D. \& $\mathrm{Ng}$, D. 1992: Distinguishing between "preference" and "motivation" in food choice: an example from insect oviposition. - Animal Behaviour 44: 463-471.

Stamp, N. E. 1981: Effect of group size on parasitism in a natural population of the Baltimore checkerspot Euphydryas phaeton. - Oecologia 49: 201-206.

Thomas, C. D. \& Singer, M. C. 1987: Variation in host preference affects movement patterns within a butterfly population. - Ecology 68: 1262-1267.

van Nouhuys S., Singer, M. C. \& Nieminen, M. 2003: Spatial and temporal patterns of caterpillar performance and the suitability of two host plant species. - Ecological Entomology 28: 193-202.

Williams, K. S. \& Gilbert, L. E. 1981: Insects as selective agents on plant vegetative morphology: egg mimicry reduces egg laying by butterflies. - Science 212 : 467-469.

Wise, M. J., Kieffer, D. L. \& Abrahamson, W. G. 2006: Costs and benefits of gregarious feeding in the meadow spittlebug, Philaenus spumarius. - Ecological Entomology 31: 548-555. 